\title{
LA SOLIDARIDAD OBRERA DE PIERRE LEROUX: UNA EXPLORACIÓN DE LA FRATERNIDAD Y LA AMISTAD ENTRE LA FILOSOFÍA SOCIALISTA DE PIERRE LEROUX Y LOS TEXTOS DE LA PAROLE OUVRIÈRE
}

\author{
The Labor Solidarity of Pierre Leroux: Exploration of Fraternity and Friendship between the \\ Socialist Philosophy of Pierre Leroux and the Texts of La parole ouvrière \\ Juan Pablo Yáñez Godoy ${ }^{1}$ \\ jpabloyg@gmail.com
}

\section{Resumen}

Este artículo explora la conceptualización de la experiencia de la solidaridad que se da en dos escenas de escritura, si bien contiguas, diferenciadas. Una de ellas es la que nos ofrece Alain Faure y Jacques Rancière en la antología de textos obreros que lleva por nombre La parole ouvrière. Contexto donde rastrearemos los elementos que articulan determinada noción de solidaridad y que se muestra en la base de una de las propuestas más significativas del movimiento obrero francés de la primera mitad del siglo XIX: la configuración de la Asociación como una "práctica de resistencia". Analizaremos los obstáculos que enfrenta esta empresa colectiva, concentrándonos en la crítica a la caridad burguesa y la denuncia del egoísmo como elementos destructivos del movimiento obrero. A partir de ese estadio, nos aproximaremos a nuestra segunda escena, representada por la Doctrina de la Humanidad que nos propone el "filósofo obrero" Pierre Leroux, donde examinaremos determinados antecedentes y proyecciones de la solidaridad en tanto fundamento de un sistema filosófico socialista.

Palabras claves: obreros parisinos del siglo XIX, Asociación, solidaridad, socialismo, Pierre Leroux.

\section{Abstract}

This paper explores the conceptualization of the experience of solidarity, that we can found in two scenes of writing, while contiguous, yet sufficiently separated and distinguishable. One of them is offered by Alain Faure and Jacque Rancière in La parole ouvrière, anthology of laborer texts of the first half of the XIX century. In there our objective is to track certain elements that configure the notion of solidarity and that are in the foundation of one of the most significant proposals of this historic moment: the Union, L'Association, as form of "praxis of resistance". We will analyze the obstacles facing this collective enterprise, focusing on the criticism of bourgeois charity and the denunciation of selfishness as destructive elements of the labor movement. From that notion, we propose an approach to our second scene, represented by the Doctrine of the Humanity, proposed by the "labor philosopher" Pierre Leroux, where we will examine certain antecedents and projections of solidarity as the foundation of a socialist philosophical system.

Keywords: Parisian workers of the 19th century, Union, solidarity, socialism, Pierre Leroux.

Fecha de Recepción: 16/04/2018 - Fecha de Aceptación: 16/06/2018

1 Licenciado y Magíster en Filosofía por la Universidad de Chile. Doctorando en Filosofía Política en la Université Paris Diderot, Francia (Becario CONICYT) y miembro del Grupo de Investigación sobre la Autoridad y lo Político de la Universidad Academia de Humanismo Cristiano, Chile. 
El siguiente texto propone la exploración de una experiencia probablemente común, compartida o al menos lo suficientemente contigua para ser así considerada, aunque expresada justamente en el cruce entre dos dimensiones ciertamente distinguibles o más bien diferenciables. Experiencia que se inscribe justamente en el cruce, que trabaja en la "barrera que separa a aquellos que piensan de aquellos que trabajan con sus manos" (Rancière 1981 22). Un análisis bastante sucinto y acotado de un momento en el cual la experiencia de la actividad filosófica compartió el mismo suelo que una forma particular de experiencia política, generando un desplazamiento de esa distancia y tensión vital que entre ambas actividades se dispone, hacia los horizontes de un diálogo cruzado, probablemente ameno sino fraternal. Proponemos pues una suerte de pequeña radiografía que encuentra un cruce de caminos entre, de una parte, la experiencia de los obreros parisinos del siglo XIX recogida por Alain Faure y Jacques Rancière en La parole ouvrière (Faure, Rancière 2007), y de otra, en la obra del "filosofó proletario" y a su vez "inclasificable" Pierre Leroux.

En ambos registros, la experiencia que produce esta confluencia es nombrada solidaridad y se muestra como un elemento fundamental tanto de la doctrina propuesta por P. Leroux en La Humanidad (Leroux 1985) a la vez que es conjurada por estos escritos obreros como una manera de denominar una forma específica de las relaciones humanas, que bajo su particular contexto histórico, parecen testimoniar una acepción de la fraternidad, ese otro gran nombre que se aparece luego de la Revolución francesa junto al de igualdad y libertad. Solidaridad que inaugura, tanto para los obreros como para Leroux, una dimensión con un potencial inédito, capaz de reconfigurar la manera en que nuestro lazo con los demás es entendido y que, por lo mismo, permite pensar de manera correcta, verdadera, los espacios de igualdad y de acciones en conjunto que los sostienen.

En ambos casos, tanto en la doctrina de Leroux como en el testimonio de las preocupaciones obreras, la solidaridad se muestra como ese nombre casi sagrado, ${ }^{3}$

2 El siguiente trabajo comenzó en un seminario de Anne Kupiec, en Paris Diderot, llamado "Escritura y política", abocado a la relación de los textos obreros con determinados paradigmas de lo político. Luego del seminario, en lo que sería nuestra última reunión, le comenté las ideas generales de esta investigación a Étienne Tasin, quien respondió de esta manera: "ça!; c'est ça!" Valga el presente trabajo como una respuesta póstuma a estas palabras.

3 Nunca está demás, especialmente en nuestro contexto, recordar las palabras que en 1548 (aprox.) escribe Étienne de La Boétie sobre la condición sagrada de la amistad: “La amistad es un nombre sagrado, una cosa santa. Ella sólo existe en la gente de bien. Nace de una mutual estima y se mantiene menos por los beneficios que por la honestidad. Eso que encuentra a los amigos, es el 
correcto y específico, que me permite pensar la relación con los demás fuera y contra toda forma de dominación. Nombre que adopta una forma determinada y finita, nos dirá Leroux, bajo la figura de la Asociación, pero que, en su relación con la sociedad, con el mundo y por los nuevos horizontes que en él se desplazan, adquiere una proyección hacia un futuro donde los riesgos son tan altos como las expectativas.

Tal como Rancière nos señala, estamos ante un momento extraordinario, en los albores de la revolución industrial, donde los cambios en las condiciones de producción y la consiguiente transformación de la concepción del trabajo abren el porvenir a, al menos, dos proyecciones "igualmente posibles" (Faure, Rancière 18). Un porvenir capitalista, donde la "reorganización de proceso de trabajo", trastorna las relaciones filiales entre los obreros al mismo tiempo que "refuerza la disciplina" en sus espacios de trabajo, promoviendo la "instauración de una nueva esclavitud" (Faure, Rancière 19). Futuro capitalista que en el mismo momento histórico se articula contra un otro porvenir, cargado de libertad y que se vuelve posible bajo la figura de la "asociación libre y voluntaria de trabajadores" (Faure, Rancière 19), en tanto proyecto solidario, fraterno y utópico de resistencia a la dominación.

Elegimos así, como primera etapa de esta radiografía, los relatos que nos entregan las escrituras obreras, donde la solidaridad se deja leer como una suerte de respuesta ante los desafíos de la asociación y la fraternidad. Ahí esta experiencia de una asociación, basada en la solidaridad, adopta al menos dos dimensiones: la forma de una respuesta ante los peligros de disolución internas que enfrentan las sociedades obreras $y$, más interesante para nuestro caso, el modo de una contestación ante el peligro que representa la benevolencia patronal para los obreros y sus esfuerzos de asociación. Benevolencia que coincidentemente, es llamada filantropía, a ratos como una falsa solidaridad, o de manera más mancomunada como caridad. Caridad que encarna lo que nos aventuraremos a concebir como un intento de ocultamiento de lo político, un atentado contra los espacios de igualdad que los obreros persiguen y contra el horizonte utópico que en ese contexto se deja entrever.

Solidaridad contra la caridad que encuentra en Pierre Leroux una tematización más detallada, ciertamente filosófica -en la acepción socialista del término que exploraremos en su obra-, y que dispone estas experiencias, sin referencia explícita a su procedencia política, como una contradicción fundamental de la encrucijada moderna por la persecución de su ideal más propio, a saber, la idea de Humanidad. En efecto, para Leroux la necesidad de distinguir la solidaridad de toda forma limitada y corrompida, como es el caso paradigmático

conocimiento de su integridad. La garantía ahí es un bien natural, la fidelidad, la constancia. No puede existir en efecto la amistad donde exista crueldad, deslealtad, injusticia" (La Boétie 18). 
de la caridad, nace de un compromiso filosófico y político con la Humanidad, en tanto "único medio donde se desarrolla la existencia del Hombre" (Leroux 1985 100). Puesto de otro modo, la solidaridad adquiere, en la reflexión de Leroux, una potencialidad política bajo la forma de la Asociación, ciertamente obrera, a la vez que filosófica, en tanto modo de relación con lo infinito, con los demás en tanto posibilidad de ese infinito y con la Humanidad en tanto su nombre apropiado.

\section{Textos y contextos obreros}

Ante las infinitas posibilidades de lectura que ofrece la recopilación de escritos obreros que nos presentan Alain Faure y Jacques Rancière, en este caso elegimos sólo una. Acceso privilegiado a un contexto fundacional de la historia sindical, en uno de los episodios probablemente más convulsionados de la escena política de la modernidad -entre la revolución de 1830, que da comienzo a la Primavera de los pueblos y la Comuna de París -, estos cuadernos, escritos y panfletos nos ofrecen, entre este universo de posibilidades, una pequeña antología de las preocupaciones de un movimiento que expresa ya sus dificultades y detecta sus principales obstáculos. Escritos que, tal como sus compiladores nos detallan, más que amenazar, organizar o incluso conspirar, dan testimonio de una intensión más fundamental.

Los obreros nos hablan "para ser comprendidos" (Faure, Rancière 9), para experimentar probablemente por primera vez las maravillas de la publicidad moderna comprendida en su sentido kantiano: ${ }^{4}$ los rendimientos de escribir y ser leído, de aparecer como un igual ante sus iguales, de descubrir en estos pequeños espacios de publicación un lugar donde la igualdad y la fraternidad es compartida y traducida bajo las formas de las escrituras. Esta condición experimental de estos textos, su exploración de la escritura como forma de establecer y reconfigurar el lazo social, que configura las relaciones de una clase, aparece gracias a la lectura de Rancière con una potencialidad fundacional. En efecto, como un discurso que no es sino contestación a su época, las palabras obreras exploran, en la escritura, las posibilidades de "fundar a un derecho que la violencia no sabría darse a sí misma"

4 Es posible pensar que los obreros están desplazando la definición kantiana del uso público de la razón - “[E]l uso público de la razón debe siempre ser libre y sólo él puede aportar la Ilustración entre los hombres [...] comprendo por uso público de su propia razón aquel que alguien hace de ella, en tanto que erudito, y ante un conjunto de público que le lee" (Kant 45) -, en tanto están justamente poniendo en cuestión el estatuto de savant, de "erudito", "docto" o de "experto", de aquel que escribe y de quién es leído. De todos modos, es interesante notar como sus escrituras se dejan leer como una resignificación de este componente tan importante para la idea de modernidad e ilustración. 
(Faure, Rancière 10), ensanchando el horizonte de los senderos que articulan la lucha contra una forma de subyugación específica.

Fundación que pasa en primer lugar y dicho de manera quizás demasiado esquemática, por una toma de la palabra para "reconocer su lugar" (Faure, Rancière 11). Posibilidad que lejos de cerrar la escritura a una aceptación de una condición dada, abre la escena que estas revistas representan para un reconocimiento mutuo de un espacio para la igualdad. Reconocimiento que se piensa como condición para la articulación de cualquier forma de organización y que está ligado de manera manifiesta a un "rechazo a ser despreciados" (Faure, Rancière 12), a la lucha contra las condiciones de desigualdad y especialmente de invisibilidad que habitan en el espacio social que la fábrica determina.

En ese sentido, toda lucha por el reconocimiento busca, en primer término, detener un proceso de invisibilización, que tal como Rancière no sugiere, es propiamente capitalista, ${ }^{5}$ que nace de la modificación de las condiciones de producción y que atenta contra la consideración del obrero como un individuo noaislado, es decir, parte de una comunidad, de una sociedad y de una clase. ${ }^{6}$ La aparición, la necesidad de reconocerse y del paso siguiente, de asociarse, se muestra así como parte del desarrollo coherente de una lucha contra el ocultamiento y la segregación que los mismos obreros identifican como un peligro de primer nivel. Invisibilización y "mecanismo de desposesión" (Faure, Rancière 18) que opera sin fin, sin detenerse en la condición de obrero y los límites de la fábrica, sino que trasciende a su propio reconocimiento como miembro de una comunidad.

5Mientras que en los escritos obreros, Rancière, piensa el capitalismo como una reorganización del trabajo bajo nuevas condiciones que, en el contexto determinado de estos obreros del siglo XIX, se piensa como un proceso y "mecanismo de [...] desposesión" que tiene a la servidumbre como horizonte (Faure, Rancière 18) en una entrevista relativamente reciente, el mismo capitalismo es ahora abordado desde el punto de vista actual y descrito como "el mundo", "el mundo en el cual nosotros vivimos"; "un mundo sin centro" que "está en todos lados y en ninguno" (Rancière 2017 54). Desplazamiento interesante, quizás desolador, y que nos entrega un signo del carácter situado de la reflexión de Rancière a la vez que nos da una pequeña muestra del carácter extraordinario del momento bisagra que atestiguan los obreros, Leroux y parte importante de la reflexión del siglo XIX. Mismo tiempo donde se inscriben las primeras lecturas de lo que ahora podemos denominar como ciencia ficción, de las utopías socialistas y de autores como William Morris quien nos describe en News from Nowhere (Morris 2003) el viaje imaginario de un inglés del siglo XIX hacia un futuro donde el socialismo, tal como Pierre Leroux lo concibe, se ha transformado en una realidad.

6 Sobre este sentir de "clase" J. Leroux brevemente señala con respecto a las condiciones de aislamiento y de egoísmo en las fábricas: "No hay nada que responder: la clase [ahí] no existe; [en las fábricas] no hay más que individuos. La disminución de salarios tiende a este estado de cosas" (Faure, Rancière 71). 
"La soledad absoluta corrompe al hombre" (Faure, Rancière 70) nos dice en 1833 Jules Leroux ${ }^{7}$ hermano menor del para nosotros ya célebre Pierre, haciendo alusión, ciertamente, a los efectos de esta desposesión y alienación proto-industrial, pero permitiendo, además, relacionar su experiencia del trabajo en las fábricas con la de jefe de taller Émile Varin, que en 1839 va un paso más allá.

La esperanza - nos dice Varin- es ciertamente una cosa bella que nos hace soportar con resignación las enfermedades del cuerpo en la espera de recuperación, las afecciones dolorosas del alma gracias a la perspectiva de un bienestar futuro; pero la esperanza degeneraría en decepción, si ella no estuviera secundada y realizada por dos recursos que todo lo consiguen: la inteligencia y la voluntad. La voluntad depende de nosotros, ¡la inteligencia la conseguiremos! ¿No ha sido el emperador que ha dicho que la palabra imposible no es francesa? Que la acción privilegie entonces la esperanza, ya que, aislada, la pobre hija del cielo perpetúa la servidumbre al beneficio del privilegio (Faure, Rancière 165).

Me permito citar en extenso las palabras de Varin porque en ellas se revela la condición particular de un momento histórico que entrevé, en la esperanza, ya no sólo el placebo que permite sobrellevar la faena y reproducir la continua dinámica de explotación a la que están sometidos los obreros, sino una apertura inédita hacia un futuro de horizontes insospechados. En esa línea, Varin no tan sólo realiza una crítica del rol funcionario de la esperanza dentro del espacio de la fábrica, sino que nos enseña que, bien conducida, es decir condicionada por la influencia de la voluntad y la inteligencia, la esperanza se abre hacia un futuro donde lo imposible se muestra al alcance de una acción colectiva, mancomunada. Es precisamente esa condición plural de la acción obrera la que permite declinar la esperanza en futuro de una manera correcta, verdaderamente auspiciosa, porque en su versión limitada, es decir "aislada", la esperanza sólo desempeña un rol funcional a la servidumbre y el privilegio.

Este último paso resulta fundamental en la medida que nos entrega una visión, quizás un tanto panorámica, de las coordenadas en las que la acción colectiva a la que llaman estos obreros se piensa. Existe ciertamente una crítica radical a la condición burguesa, patronal y paternalista de su sociedad, pero tal como Varin lo deja entrever, los elementos que articulan esa subyugación no coinciden, primero, con una posición determinada, sino que habitan en el

7 Los compiladores de La parole ouvrière recogen extractos de un texto de Jules Leroux titludo "A los obreros tipógrafos" (Faure, Rancière 67,78), sin dar bastante referencia de su relación con Pierre Leroux. Es Ludovic Frobert (Frobert 2010) quien nos señala que Jules es el hermano menor de Pierre, impresor de profesión, fundador junto a su hermano de numerosas revistas como la Revue Independent y la Reveu Social, y que fue posteriormente exiliado a Estados Unidos. Destaco la lectura de Frobert porque agrega más elementos para el análisis de esta relación próxima y, en este caso, literalmente fraternal entre la actividad del filósofo, Pierre, y del obrero, Jules o como Frobert lo llama, de un Leroux “de una inspiración de corte más ruda y proletaria” (Frobert 77). 
aislamiento y en la ambición de privilegio. Lejos de la identificación de un "enemigo externo" en el patrón, el jefe o en la burguesía en general, Varin desprende las fuentes de la opresión de estas figuras para identificarla con una manera de disponer la relación con los demás que se basa en el egoísmo y el privilegio. La servidumbre habita no tan sólo fuera de los límites de nuestros espacios de igualdad y fraternidad, sino que se muestra como un peligro omnipresente y latente.

Al mismo tiempo, en una segunda dimensión, la acción contra estos peligros, contra esta reconfiguración de los vicios modernos, es contenible y condicionable gracias a la asociación, guiada por la esperanza, limitada y determinada por la voluntad y la inteligencia. De esta manera, la fábrica se vuelve un espacio en disputa porque es precisamente ahí donde habita el "completo aislamiento", 8 según J. Leroux, pero el trabajo mismo, resignificado bajo estas nuevas coordenadas de una acción colectiva, asociada, puede devenir en un elemento, sino El elemento, emancipador.

"El fin justifica los medios", nada más lejano al llamado de estos obreros que comprenden que la única forma de abrir el horizonte de la esperanza hacia el futuro es reconfigurando la forma de la relación que entre ellos se tiende y que se revela sólo en los espacios donde la igualdad es actualizada, compartida. Antes de examinar la forma concreta que toma esta pretensión de igualdad obrera, antes de analizar la importancia de la propuesta que representa la Asociación, me gustaría desenmarañar un poco más en detalle el proceso que acompaña a esta verdadera "práctica de la resistencia" (Faure, Rancière 31), especialmente la relación entre la palabra y su rol en la articulación del movimiento obrero.

Podemos considerar, en primer lugar y sin un orden específico, que la toma de palabra por parte de los obreros efectúa una "alteración de un campo de la experiencia"9 y de sus posiciones asignadas y determinadas, por utilizar el lenguaje rancieriano, en la medida que sus escrituras transgreden "la barrera que separa a aquellos que piensan de aquellos que trabajan con sus manos" (Rancière 1981 22). Transgresión o "proceso", por hacer un uso laxo del término, de des-

8 J. Leroux va, en efecto, aún más lejos con su descripción de la vida, ya no solamente en las fábricas, sino en el mundo moderno que estas configuran, en las relaciones que tanto maitres y obreros mantienen. Relaciones gobernadas por el egoísmo, la inéquiedad y la alienación. "No llamemos libertad a esa manera de vivir, común a obreros y a maestros; no profanemos de esto modo esta palabra. Esa no es libertad, es aislamiento, aislamiento completo. La naturaleza humana mejor organizada así se deteriora; la soledad absoluta corrompe al hombre; amarga todas sus generosas pasiones, y las convierte en veneno" (Faure, Rancière 70).

9 "En cierta medida lo que se halla en el corazón de la subjetivación son los modos de implicación. La subjetivación es la alteración de un campo de experiencia que se caracteriza por cierta distribución de las capacidades" (Rancière 2014 104, 105). 
identificación de una posición, donde sus potencialidades son reducidas desde la ejecución de una labor a los confines de una personalidad difícilmente clasificable, que muchas veces permanece anónima bajo el sello de una firma colectiva, ya sea bajo el nombre de la "federación", "asociación" o "mutual", y que por lo mismo guarda como principal atributo la puesta en cuestión del proceso mismo tras la identidad/identificación. ${ }^{10}$

En el contexto obrero que aquí nos atañe, este desplazamiento se expresa menos como una transgresión de una identidad dada que como una operación de resignificación del lenguaje, de los conceptos y del sentido de las actividades que articulan la vida de los obreros. La escritura obrera, en tanto letra precisamente escrita, disputa el espacio de igualdad que ese soporte comparte con la letra burguesa. Disputa sus significantes, sus estilos y sus modos de enunciación que es donde la asignación, la identificación y la clasificación se efectúan. En "el lenguaje burgués, en la materialdad de su letra, se dice la opresión" (Faure, Rancière 12), nos dice Rancière, haciendo referencia al conjunto de significantes que escapan a la funcionalidad determinada de sus discursos, que una vez leídos y dispuestos a la preocupación de estos obreros, abre su uso a la transgresión y reapropiación.

Así, los apelativos "revoltosos", "esclavos", "insurrectos" y hasta "bárbaros" (Faure, Rancière 13) que representa cabalmente la violencia de la asignación, hacen aparecer al mismo tiempo la división que separa a aquellos que trabajan precisamente "con sus manos", de aquellos que no, o aquellos que se revelan, que rehúsan de su identidad asignada, de aquellos que aún padecen el aislamiento. Nombres que, una vez dentro de un espacio de resignación, ya en la dimensión del discurso y por tanto de la crítica o la contestación, ofrecen la oportunidad de ser rechazados, censurados o reapropiados como catalizador de un movimiento. ${ }^{11}$

Reapropiación y desidentificación que lo escritos que aquí nos ocupan testimonian como una reflexión abierta y colectiva sobre las relaciones entre los obreros, sobre las dificultades para modular estos lazos de manera fraterna y para encauzar su acción colectiva por un objetivo mancomunado. Estas son

10 Me parece que dar pie a una discusión sobre el o los sentidos de la reflexión de Jacques Rancière sobre el concepto de subjetivación, donde es circunscribible este proceso de des-identificación, puede desviar nuestra reflexión hacia otros mares, precisamente por la potencia de sus posibilidades. Me permito, en cambio, citar la acepción de Étienne Tassin sobre este proceso, que lo describe en profunda afinidad con nuestro contexto. “La subjetivación designa el surgimiento - la revelación - de una singularidad no-identificable: no identificable a las comunidades dadas [...] y no identificable a las "cualidades" o "atributos" de los tipos de repertorios" (Tassin 127).

11 Rancière da cuenta de este desplazamiento a partir del uso que los obreros efectúan de la palabra "esclavo", la cual, una vez proferida por un ministro de Estado ( $i$ "son ustedes acaso "esclavos" de este operador político?") en una reunión con una delegación obrera que quería evitar el cierre de los Ateliers nacionales, es levemente descontextualizada (“¡el ministro nos ha llamado “esclavos"!") para servir como catalizador de una insurreción armada (Faure, Rancière 13,14). 
precisamente las líneas directrices de La Asociación, propuesta obreras que se piensa, como anteriormente enunciamos, como una "práctica de resistencia" no tan sólo contra una opresión pensada en abstracto, sino precisamente contra el aislamiento y soledad absoluta que la alternativa capitalista introduce en el mundo moderno.

\section{La Asociación y la pesadilla obrera}

Todos para cada uno, cada uno para todo (Emblema de la Asociación de Estibadores y Cargueros del Puerto de Havre)

Una de las preocupaciones constantes en los textos obreros que aquí analizamos junto con la tematización de los formas y dificultades de la organización, la denuncia y puesta en cuestión de la explotación y la crítica a la clase burguesa-, es la demostración de la necesidad de unión dentro de una figura concreta. ¿Por qué es necesario organizarse? Pregunta tan simple como esencial y que bajo el contexto disyuntivo y convulsionado que estos escritos testifican, se formula en un esfuerzo manifiesto por resignificar la relación entre los obreros, el trabajo y el progreso. Pues, ¿cómo pensar el rol y responsabilidad de la clase obrera con el futuro más allá de una relación de subordinación? ¿Cómo pensar el trabajo bajo otra significación, bajo otra afección, que no sea el sufrimiento? ¿Por qué el sufrimiento y no más bien el placer? ${ }^{12}$

Preguntas fundamentales aunque desbordantes y que bajo este contexto específico no tienen un sentido único. Los textos dejan entrever esta polifonía, problematizando la relación del trabajo con sus efectos en orden de reconfigurar el rol y sentido de una clase. En ese sentido Gosset, quien nos presenta una suerte de canon del buen Compañero a partir de un verdadero ejercicio crítico de desmontaje, en 1842 nos señala: "la sola ambición de un verdadero Compañero debe ser una devoción sin límites por el mantenimiento y glorificación de su deber" (Faure, Rancière 137), pensando, en primer lugar, ese deber más allá de las condiciones de subyugación al que coyunturalmente está sujeto. En segundo lugar, Grosset invoca esta devoción al deber y al trabajo contra toda forma de división interna, contra todo egoísmo que piense esa relación de forma limitada o interesada,

12 Inspirado en las ideas de Fourier - “(utopista francés (1772 -1837) que insistía que el trabajo no era inherentemente inatractivo. Bajo las circunstancias apropiadas -verdaderas podrías agregar siguiendo a P. Leroux - la labor podría transformarse en una fuente de placer y de auto-realización, que los talentos se multiplicarían y que la productividad aumentaría" (Morris 115) - William Morris nos pregunta en News from Nowhere: "la recompensa del trabajo es la vida misma. ¿Es que esto no es suficiente?" (Morris 79). 
por seguir utilizando el lenguaje kantiano. Advertencia que apunta contra el egoísmo, pero también contra la división de las pequeñas escuelas, de los cultos y con ello del lugar de la religión en el espacio común. ${ }^{13}$

Como Pierre Moreau en 1843 lo señala, es la experiencia que ha enseñado a los obreros que en tanto existan privilegios y distinciones en las sociedades obreras, existirán “discordias y combates" (Faure, Rancière 141), indicando no tan sólo la importancia de la igualdad como condición para relacionar a una clase con un futuro diferente, sino la fuente de este conocimiento. Charles Noiret, en 1841 especifica este punto: "nosotros tenemos el instinto de lo verdadero, de lo bueno, de aquello que es bueno para todos" (Faure, Rancière 86), justo antes de afirmar que "la propiedad, la explotación, como el trabajo, es toda una convención, que no tiene nada de natural; y siendo una convención, es posible concebirla de otro modo" (Faure, Rancière 90). Puesta en duda de la condición dada no tan sólo del trabajo, sino de la dominación de la que éste está sujeto y que lleva a Moreau a una reconducción de una importancia crucial: "el trabajo es la única fuente de producción", no obstante "los más afortunados se han apropiado de los instrumentos de producción" y con ello han producido "la explotación del hombre por el hombre". Frente a ese escenario, es necesario efectuar una reconducción de la producción del trabajo donde "quien no produce, no tiene el derecho a consumir" (Faure, Rancière 91).

La Asociación se comienza a mostrar, así como un esfuerzo por repensar la relación del trabajo con su fuente, con aquellos que producen la riqueza. A la vez que busca, tanto ofrecer un espacio de resistencia ante el aislamiento y el egoísmo, como reconfigurar la relación de los obreros con un panorama en lo absoluto parcial o que al menos se extiende mucho más allá de las fronteras de la fábrica.

En este sentido, si seguimos a Jules Leroux, su exhortación a la organización obrera se articula como la única respuesta coherente, ya no tan sólo a la transformación de los oficios en abstracto o según una visión más general, sino ante la amenaza creciente de la desaparición específica del trabajo de impresor, ${ }^{14}$ pero con consecuencias para "una clase entera". ${ }^{15}$ Es precisamente en esa

13 "Si los Compañeros, haciendo sus ceremonias, cumplen un deber religioso, la soledad y el recogimiento les serán necesarios para bien celebrarlos, ya que distraídos por las bromas de un auditor que no les comprende, alcanzarán difícilmente el objetivo de su intensión" (Faure, Rancière 137).

14 "Hoy por hoy, no se trata del interés [particular] de los tipógrafos; eloficio en las imprentas son eliminados" (2007 68).

15 "El principio de 1830 marca un cambio significativo para el oficio tipográfico, de las técnicas de impresión, en la edición y en las librerías que evolucionaron, a partir de ese momento, muy rápidamente. Nos situamos así en un contexto de dudas para los obreros tipógrafos que se enfrentan a una crisis que les supera y que amenaza con una miseria capaz de tocar a una 'clase entera'” (2010). 
articulación, de una problemática particular comprendida en un contexto universal, síntoma de un fenómeno mayor, ${ }^{16}$ en el que la Asociación en tanto "afirmación específica de las relaciones de igualdad y de independencia" obrera (2007 32) se presenta como la "buena solución” (2007 31).

Así, en la clave de lectura de Frobert, esta transición desde una problemática sectorial, particular, a una preocupación por el mundo y la humanidad, por su porvenir y su bienestar, se articula como crítica al anclaje específicamente individualista que ha tenido determinada configuración "contingente", como nos diría Moreau, de la sociedad. Particularmente, de las sociedades que son protagonistas de un inédito proceso de industrialización y que han articulado su historia reciente a partir de una lucha por la emancipación y la libertad. La Revolución, en este caso francesa, ha de cierto modo desviado nos dice Frobert, por su visión limitada por la figura del "individuo-propietario", las posibilidades que comporta este momento de ruptura con el pasado.

El apego a la figura del individuo y la reconducción de la libertad a los contornos de una identidad que se concibe a partir de la separación, de la propiedad y sus derechos, han dispuesto las condiciones para la configuración de un orden social y su economía, foco de interés para Jules Leroux, a espaladas de la sociedad y de su medio natural, donde sus diferentes dimensiones se inscriben. Esa escisión del individuo de su contexto, de su naturaleza nos dirá en un sentido más amplio Pierre Leroux, posibilita la diferenciación de la sociedad en clases, por una distribución que responde el proceso productivo, ${ }^{17}$ que propicia el “acaparamiento y la posesión” (Frobert).

De esta manera, la atención a la separación y denuncia del egoísmo, como forma de pecado contra la fraternidad, se deja leer con facilidad en los textos obreros. "¡Al egoísmo, plaga espantosa de la humanidad, opongamos la abnegación, el sacrificio, las únicas potencias verdaderas de la acción!" (Faure, Rancière 165), nos dice con un tono bíblico el mismo Varin, al mismo tiempo que

16 Es interesante notar que esta condición de precariedad para J. Leroux no es tan sólo propia de los obreros, sino también de sus patrones. La diferencia parece radicar en las redes de apoyo que los obreros pueden tener, bajo la forma de la Asociación, y que los patrones deben reemplazar con una acumulación de riqueza. De todos modos, dice Leroux, si un patrón cae en desgracia “bien lejos de venir en su socorro, cuando su condición es sabida por sus congéneres [...] estos alejan de él todo crédito; le forzan a vender; y ese hombre vuelve a menudo a nuestras filas; por sustentar a su familia [...] se hace obrero" $(200769,70)$.

17 Jules Leroux nos ofrece su panorámica de la distribución de la sociedad en el siglo XIX: “En la sociedad industrial actual, la posesión de instrumentos de trabajo es efecto de la propiedad (el propietario) de la locación (el jefe) o del que las usa (el obrero). El propietario es ocioso y no hace más que consumir [...]; el jefe trabaja sobre todo para transferir las obligaciones de la concurrencia sobre los obreros; los obreros son finalmente los que utilizan los instrumentos de trabajo (que toma prestados) para producir la riqueza" (citado por Frobret). 
llama a luchar contra este vicio con las armas de la instrucción, del "perfeccionamiento de nuestra inteligencia" y del conocimiento de "derechos y deberes sociales" (Faure, Rancière 164). Proceso de instrucción que dispone así la unión obrera "no como una tribuna para discutir [...] palabras de odio", sino como un espacio para la formación, bajo la figura de una "escuela mutual" (Faure, Rancière 164).

En esa misma línea se escriben las Disposiciones Generales de la Asociación de Estibadores y Cargeros del Puerto de Havre, que estima como medios para conseguir "la liberación del trabajo y la abolición de la (condición de) salariado", la "igualdad ante el trabajo", ciertamente la "solidaridad", pero también la "reunión de fuerzas y de inteligencias" (Faure, Rancière 320). Interés en la formación que, sumado a la red de protección, especialmente económica ante desastres y siniestros personales, materializan la Asociacón como "práctica de resistencia". En esa línea, los obreros portuarios de Havres proponen "compartir entre nosotros nuestro salario, resultado de los trabajos libremente consentidos" (Faure, Rancière 321), bajo el principio de "Todos para cada uno y cada uno para todo" (Faure, Rancière 322) inscripción que todavía se deja leer bajo el escudo de La Fraternal y con algunas modificaciones en los antiguos edificios de otras cooperativas obreras. Principio igualitario que sintetiza la necesidad de asociación a la vez que reafirma el compromiso fundacional de estos espacios con cierta idea de totalidad, o como más precisamente lo enuncia Varin los Compañeros trabajan por la "humanidad" (Faure, Rancière 139).

Aislamiento y el egoísmo se muestran, así, como los enemigos de este insipiente "sistema que garantiza la solidaridad, que concilia sin cansancio libertad e igualdad" (Frobert) que describe la figura de las Asociaciones obreras. Ahora bien, ¿cómo interrumpir este proceso de organización? ¿cómo atentar contra la construcción, tan diversa como fraternal, de esta alternativa solidaria contra el individualismo y el privilegio? En las múltiples denuncias de desidia y combate dentro de la gestación de estas sociedades mutuales existen dos preocupaciones que identifican, a mi parecer, de mejor manera el atentado contra la noción de solidaridad que éstas nos proponen.

La primera de ellas revela un aspecto particular de la subyugación, que en este contexto se declina bajo el nombre de paternalismo y que configura de una manera específica la relación que los patrones ejercen sobre sus subordinados. "[L]a miseria aumenta en razón del incremento del número de nuestros padres", se señala en el diario De l'Atelier (Faure, Rancière 172), haciendo hincapié en la asimetría no tan sólo en la repartición de la riqueza, sino en la restricción y control de las inteligencias que la producen. Obreros que se sienten tratados como "infantes en adopción" (Faure, Rancière 173), escenario adverso que explica en gran medida la valorización de la instrucción, así como también la creación de 
espacios de escritura y lectura. Espacios que ponen en cuestión la subyugación de la condición obrera a una mera fuerza productiva, reducida a una condición que $P$. Leroux llamará "indirecta", es decir, entendida no como un fin en sí misma sino como medio para un fin limitado, para una riqueza privativa.

Paternalismo que adquiere su forma más específica bajo el nombre de filantropía y que más que identificar una o varias instituciones patronales de ayuda y socorro, revela una forma de ejercer la subyugación y la asimetría particularmente peligrosa para las posibilidades de una Asociación. Gosset, parece identificar el problema general con el esfuerzo filántropo de estas sociedades de socorro, señalando que "toda cosa buena, a cuya aplicación, mal dirigida, carezca de equidad, se destruye en su principio" (Faure, Rancière 128). Destruye el principio precisamente de esa bondad inicial, primera, revelando que el problema con la filantropía no parece ser, en una primera lectura, sus buenas intenciones, sino el suelo de desigualdad sobre el que éstas son dispuestas.

Apuntando en esa línea Gosset hace un llamado a una "verdadera filantropía" (Faure, Rancière 128), a la posibilidad cierta de una relación, esta vez basada en una otra idea de la solidaridad, que presuponga la igualdad como condición de la relación. No obstante, la peligrosidad de la filantropía no radica simplemente en el suelo de desigualdad que la configura, sino en sus efectos sobre la clase obrera. Consecuencias que se deja leer en estos escritos cuando el problema de la caridad aparece bajo la figura de una "verdadera pesadilla del clase obrera" (Faure, Rancière 172):

El filántropo padre de los obreros es una pesadilla en [varios] sentidos: se esfuerza en esconder la herida que devora a la clase obrera, y, volviéndose hacia las clases altas, él les dice: "la herida está curada", o: "la herida está en vías de ser sanada; no se inquieten, yo tengo el secreto de volver al pueblo contento, humilde y obediente (Faure, Rancière 173).

Así, esta generosidad patronal y paternalista atenta contra la clase obrera en un doble sentido. Por una parte, genera una imagen, bastante pública, de un patrón benevolente. Sin alterar la asimetría de la relación de subyugación y sin emplazar el lugar de esta relación en el espacio que le es propio, el de la fábrica, el filántropo establece un vínculo de generosidad, de benevolencia, que sirve para encubrir la catástrofe, la injusticia primera. ${ }^{18}$ De este modo, el sufrimiento obrero, afección que se deja ver en estos relatos a cada instante, es disimulado con un acto que en nada

18 “El obrero no tiene nada que perder, su suerte no sabría ser peor; no desando la conmoción, tampoco le teme, no más, porque con cada catástrofe cabe la esperanza de ver cesar el estado intolerable de las cosas del cual él es la víctima y donde se puede liberar de la carga de miseria que haca tanto tiempo pesa sobre él" ( Faure, Rancière 27) 
remedia la condición de estas industrias, que "nos son para nada caritativas y fraternales" (Faure, Rancière 172).

Operación de encubrimiento de estas empresas caritativas que no se limita, ciertamente, al exterior del espacio de las fábricas. No es tan sólo una operación que se pone en juego para donar una impresión pública de justicia o de solución al "problema". Esta forma de sostener la desigualdad y de, quizás, hacerla sustentable, permea también la articulación interna de los movimientos obreros, como nos señala esta caricaturización del discurso burgués que se lee en L'Atelier:

Ustedes hablan de institución, de institución; aquello no sirve de nada a los obreros. No hay necesidad de institución; hagan como yo... yo fui obrero, yo, et ahora yo soy millonario: ¡todos ustedes lo pueden ser! [...] yo trabajé con mis manos, donde mi padre, y ahora soy millonario (Faure, Rancière 174).

La relación de la filantropía no se detiene, como es posible apreciar, en la transformación de la imagen pública de la clase burguesa. El filántropo tiene sus influencias dentro de la gestación del movimiento obrero, que demanda una reconducción y refundación de las "instituciones", por insertaran ahí un otro imaginario -ese que bien hoy en día conocemos- del esfuerzo individual, privado, que contra todas las dificultades triunfa, deviniendo un relato del éxito y el emprendimiento.

Imagen que se presenta, ante el relato de estos obreros, como una encarnación del egoísmo, un atentado contra la fraternidad, pero que adquiere una tematización más detallada en la propuesta filosófica de Pierre Leroux, etapa final de nuestro recorrido.

\section{La solidaridad obrera de Pierre Leroux}

Si bien hemos mencionado pequeñas remarcas sobre las dimensiones de la fraternidad que Pierre Leroux mantuvo con el movimiento obrero del siglo XIX literales en el caso de Jules L.-, nos abocaremos en esta última sección ya no al análisis de esto vínculos directos o, mejor dicho, explícitos. Comprenderemos, en cambio, una pequeña parte de su obra como una expresión filosófica del sentir y pensar de su época, una entrada otra para analizar la relación entre caridad y fraternidad. Encontramos pues en Pierre Leroux nuevos insumos para aproximarnos a esa experiencia de la que nos hablan Gosset, Moreua y Varin, quienes a pesar de los efectos devastadores de la filantropía, tanto fuera como dentro de los movimientos obreros, admiten todavía la posibilidad para una forma verdadera caridad.

En una sintonía afín, P. Leroux nos señala: 
La libertad humana proviene de la caridad, o de la comunión con nuestros semejantes y con el universo, al igual que la caridad resulta de un derecho individual que tenemos con esa comunidad, es decir, en otros términos, de nuestro interés y de nuestro egoísmo (Leroux 1985 159).

Este fragmento de la doctrina de La Humanidad (Leroux 1985), en un gesto un tanto críptico, explicita en efecto la contradicción que el concepto de caridad encarna. $\mathrm{P}$. Leroux, "filósofo inclasificable", nos está aquí proponiendo un análisis del fenómeno de la caridad que adopta como fuentes un examen crítico de los presupuestos y efectos del cristianismo, a la vez que deja entrever un giro y desplazamiento hacia un otro orden de experiencia.

Para Miguel Abensour -cuya obra utilizaremos de guía en este trayecto-, este desplazamiento responde a una convergencia de diferentes elementos. Existe en la obra de P. Leroux, en un estadio, una crítica profunda del rol disciplinar de la filosofía. Crítica que se inscribe dentro de una operación más amplia contra el sentido limitado ya no tan sólo de la filosofía, en tanto disciplina o de nuestra relación con el conocimiento, sino de la naturaleza humana, la cual es pensada a partir de una tríada indivisible formada por la "sensación - sentimiento conocimiento" (Leroux 1985 153). Convergencia que aparece como parte de la propuesta de Leroux por hacer de la filosofía una "ciencia de todo, ciencia de la vida" (2013 115), es decir, una exhortación a borrar las barreras que la determinan como disciplina separada de su contexto y de sus desafíos. Esta versión disciplinar en efecto, adopta para Leroux el nombre de "filosofía funcionaria", 19 en tanto no tan sólo adopta un rol distanciado de su contexto y de su "medio", sino que en esa separación se vuelve un dispositivo de reproducción del orden social.

La filosofía de Leroux, por tanto, adopta como punto de partida un compromiso con idea específica de universalidad, máxima que la dispone contra toda forma de limitación. ${ }^{20}$ Es en ese sentido que Abensour lee en Leroux una invitación a la "no-filosofía", por su apertura a un "no-lugar"21 (Abensour 2013 98), entreviendo en él un pensador que ha adoptado ya no un compromiso con una "necesidad académica", con una "empresa académica", sino con una "necesidad

19 Crítica a la disciplina filosófica y su rol funcionario que se expresa como una lucha contra el "eclecticismo" que Leroux lleva a cabo en un contexto de "institucionalización de la filosofía a la sombra del Estado por la mediación de la Universidad" (Abensour 2013 178).

20 "la producción filosófica es el fruto de una dialéctica entre el yo y el nosotros"; "Los filósofos no salen de la tierra como callampas, la filosofía no es exterior al mundo". (Abensour 2013 109)

21 En su entrevista con Michel Enaudeau, Miguel Abensour da algunas pistas sobre esta articulación entre el no-lugar de la utopía y la manera en cómo este es incorporado al corpus de una reflexión sobre el presente, llámese esta filosofía en el caso de Leroux o literatura en William Morris. Abensour utiliza para describirlos la imagen del "verdadero discípulo", quien "es aquel que emprende la marcha hacia lo desconocido [...], y no aquel que subsume lo desconocido en los confines de lo ya conocido" (Abensour 2014 303). 
de la Humanidad" (Abensour 2009 60). Estas palabras de Feuerbach jamás fueron mejor aplicadas a la obra de un filósofo como en Pierre Leroux, quien entreteje su propuesta a partir de la figura de la síntesis entre la experiencia material del movimiento obrero de una época, la experiencia moral de su propuesta "socialista" 22 como una "nueva religión de la humanidad" (Abensour 2013 101) e intelectual, escribiendo la doctrina de este nuevo concepto que se revela ante él como un elemento inédito en la historia de la emancipación humana. Tal como Abensour nos señala, estamos con Leroux ante una filosofía "mixta" (Abensour 2013 115), una convergencia entre ciencia, arte y conocimiento, pero motivada, a cada momento, por el sufrimiento de su época.

Ahora bien, ¿cómo entender esta condición mixta dentro de la lectura de la caridad? Si seguimos la pista que nos deja Abensour y si asumimos que la filosofía de Leroux surge de una manera fundacional como respuesta al "sufrimiento humano" (Abensour 2013 115), en tanto que experiencia de una época, podemos comenzar por interrogar el sentido del sufrimiento mismo.

En un gesto extrañamente similar al que describe Rancière sobre los textos obreros, la Doctrina de Leroux, antes que denunciar, denostar, repudiar o culpar a una clase, comprende el sufrimiento como una expresión de la "horrible imperfección de nosotros mismo" (Leroux 1985 35). Imperfección que proviene ya no de un mal original, de una condición dada o de un fundamento trascendente, sino de un arraigo en lo que Leroux llama sí-mismo. Esta figura del apego a sí, en los contornos del yo -cierta forma de lo que podemos entender como un "perseverancia en el ser"-23, surge a partir de una suerte de imperfección en la manera de comprender nuestra conexión lo que Leroux denomina como "medio", pero de forma más persistente bajo el título de "naturaleza".

Sin pretender dar una definición cabal de la concepción lerouxiana sobre la naturaleza, podemos sí notar una primacía de la relación y el lazo por sobre cualquier forma de identidad o sustancialidad fija e inmovil. Leroux admite de hecho una dimensión doble en la natureleza humana, objetiva, en tanto relación con todo aquello que se emplaza fuera de los contornos del yo, y subjetiva, en tanto

22 Existen bastantes referentes que afirman que Leroux es el creador de la palabra "socialismo", véase (Abensour 2013), incluyendo al mismo Pierre quien señala: "Saint-Simon había en efecto sido el Profeta de eso que hoy en día uno llama (y yo estoy orgulloso de haber creado la palabra) el SOCIALISMO" (Leroux 2013 129, énfasis mío).

23 En un contexto ciertamente diferente, pero con un lenguaje extrañamente familiar al de Leroux, en su fundamental reflexión sobre Lévinas y la importancia de la condición política de su obra, Abensour señala: “ «el Yo es cuestionado por el Otro de manera excepcional», como si sufriera una torsión que la arranca del movimiento espontáneo de la perseverancia en el ser, [...] hasta el punto de hallar la idea de infinito en la relación del Yo con el Otro. El Estado descentrado [...]" (Abensour 2007 306). 
relación con una interioridad que, de todos modos, se define en razón de su potencialidad de relación con la realidad que la significa. Así, la condición tripartita de la naturaleza humana, de ser "sentimiento -sensación - conocimiento" disponen la realidad interior, bajo esta propuesta de subjetividad bajo la figura del "yo", ante la realidad exterior, comprendida como medio donde todo, todos lo que existe, adquiere su significación debido a su relación con esta idea, móvil e infinita, de Humanidad. Realidad que es definida así como "el medio donde la existencia [todas ellas] se desarrollan" (Leroux 1985 100), como "ser ideal compuesto de una multiplicidad de seres reales" (Leroux 1985 196). Dimensión del presente que se presenta como siguiendo el esquema de esta doble dimensión, de forma subjetiva como "ser virtual" 24 e "infinito", pero de manera objetiva como "nuestro semejantes", es decir todo aquello que comparte a la humanidad como medio de desarrollo, todo lo que está por tanto "fuera de nosotros", pero también en nosotros y que gracias a la "fuerza activa de una época" (Abensour 2013 112), se ha revelado como una figura realizable, experimentable.

De este modo, en una propuesta que desplaza la disciplina filosófica en una doctrina de una "nueva religión, una religión de la humanidad" (Abensour 2013 101) - comprendida como una expresión integral de su apuesta socialista-, que reconduce y organiza la discusión sobre el sufrimiento. Recalibra mejor dicho su carácter "necesario" (Leroux 1985 38) a una expresión contingente, propia de una época que no todavía no ha reconducido la existencia de las realidades que la configuran, de sus instituciones y de quiénes las significan, a la relación verdadera e ilimitada que les da sentido. Destaco ambos términos porque, como podrá apreciar el lector atento, nos encontramos ante las mismas problemáticas que expresan los escritos obreros: por las instituciones, por la creación de una Asociación como fundación de una nueva forma de entender el trabajo y las vidas atadas a éste; acompañada de un desmontaje por reconducir no tan sólo el trabajo, sino los lazos humanos que lo configuran, a una significación verdadera.

Es en esa línea, bajo la forma de un contra la ilimitación, que Leroux nos propone, en primer lugar, un ejercicio de reconducción de las estructuras que configuran la sociedad a su expresión no limitada, es decir, a su reconfiguración en pos de una relación con la Humanidad. Reconfiguración que se efectúa bajo un

24 El estatuto de esta condición virtual de la humanidad encierra una fecundidad teórica sin límites. ¿Cómo pensar la relación entre el yo, su comunidad y la realidad infinita que los significa a partir de una conexión virtual, que entrelaza las subjetividades, aunque de manera correcta y verdadera, bajo los principios de una solidaridad colectiva y organizada? ¿Es posible entrever rastros y actualizaciones de este tipo de relación hoy en día? ¿Son las comunidades libres, cuyas primeras formulaciones modernas justamente nacen en esta época y coordenadas, un posible ejemplo de esta relación, de su puesta al día en nuestro contexto? Rastros de una "vida presente que no es tan sólo presente, sino que es virtualmente eterna" (Leroux 1985 174). 
"derecho del hombre, conforme a la esencia y necesidad natural, de comulgar con todos sus semejantes y con todo el universo" (Leroux 1985 145). Derecho universal que se traduce a un derecho objetivo, es decir hacia el exterior (del ser), como un principio regulador de la "familia, la patria y la propiedad" (Leroux 1985 145). Formas todas de la expresión de una relación con el medio contingentes, es decir reales pero situadas y que por lo tanto necesitan de una traducción ante el nuevo desafío que la Humanidad emprende.

Es este, en efecto, uno de los elementos que el fragmento anteriormente citado expresa, en la medida que "familia, patria y propiedad" representan una expresión del derecho individual, que debe ser retransportado a su relación universal. En ese tránsito y si tomamos como ejemplo la figura de la familia -de no poca importancia para articular, por ejemplo, una crítica al paternalismo-, Leroux demuestra las limitaciones de su formulación moderna. Dicho de otro modo, la familia, en su versión de unidad limitada, revela como uno sus elementos determinantes la "limitación de todo [derecho] al nacimiento", a una condición local y contingente, acompañada de una "subordinación de los hijos a la figura del padre", sumado a una "transformación de los hombres en herederos" (Leroux 1985 142).

Estas tres condiciones representan tres formas de limitación e identificación de los seres humanos a su condición dada y fija, en desmedro de su condición móvil, en tanto seres actuantes y partes fundamentales de un futuro a construir. Apego al nacimiento que determina así una sujeción al nombre, al apellido; subordinación al padre que introduce la coerción y la dominación, "la desgracia sobre la tierra" (Leroux 1985 143); y a la herencia en tanto reducción, primero, de la temporalidad a los confines de la sangre y su descendencia, y después a la propiedad, como escisión y clasificación de lo que existe en razón de un interés privado.

Así, bajo el horizonte de un ejercicio de desmontaje contra la desgracia y contra toda forma de "rechazo del infinito, del progreso" (Leroux 1985 143), es que Leroux arriba al cristianismo, en tanto expresión epocal de una idea particular de la humanidad. ¿Qué es lo que este filósofo obrero ve en el cristianismo? Bajo el formato de la triada, que en su obra aparece por todos lados, Leroux distingue tres elementos. Primero, detecta, como estadio inicial de la doctrina cristiana un desprecio por el yo, "ustedes no se aman verdaderamente" (Leroux 1985 162), que se expresa como una displicencia del cuerpo en pos de un "sí mismo abstracto", versión del "alma" separada del presente. En segundo lugar, el cristianismo piensa la relación con los demás, que es donde reside para Leroux la única entrada para participar de la experiencia de la Humanidad, como un lazo "indirecto", que comprende al otro no como un ser en sí mismo, sino como un fin para alcanzar, nuevamente, una realidad abstracta y desarraigada del mundo. Finalmente, Leroux 
denuncia al amor que los cristianos siente por Dios como una versión "egoísta", como una "forma de amor a sí mismos" (Leroux 1985 162).

Puesto de otra manera, el cristianismo oculta la posibilidad de actualizar la idea virtual de la humanidad, su forma subjetiva que habita en cada uno de nosotros, al despreciar la comunidad concreta que es configurada por ese lazo humano. Para Leroux la relación con cualquier idea de Dios, del cielo y de la misma Humanidad, es definida a partir de la experiencia del infinito, lazo que se realiza por la conexión ya no con el Todo de manera directa, acto siempre abstracto, sino con todos los seres que componen, de manera concreta, esa realidad. Figura del todos que podemos pensar contra el Todo: "el Ser infinito no se manifiesta a usted sin un usted y sin los otros" (Leroux 1985 162), donde "[e]l cielo, el verdadero cielo, es la vida, es la proyección del infinito en nuestra vida" (Leroux 1985 178).

Comunión con los otros que toma el "termino general de amor" aunque de forma objetiva, es decir situada y presente, adquiere a veces el nombre de "amistad" (Leroux 1985 164) y de forma más precisa y a la vez compleja, de Asociación en tanto forma activa e organizada de la solidaridad. Solidaridad que aparece como una expresión de una relación con el otro entendido ya no en un sentido limitado e indirecto, es decir que ya no ve en su figura un medio para otro fin, sino que comprende que ahí habita una conexión con una realidad que va más allá del yo y el tú y que porta consigo la posibilidad de desplazar el horizonte de sentidos hacia su fundamento verdadero, ilimitado.

Puesto bajo la forma de esta realidad doble, la solidaridad, de manera subjetiva, se muestra como la experiencia de una constitución de lo que podemos denominar como posición de sujeto, del yo como lo expresa Leroux, que se articula en razón de la conexión y el lazo con una unidad mayor. Realidad universal abierta y que, en tanto expresión del infinito, dona a esta posición, a esa existencia particular, su sentido propio, su condición de humano podríamos decir, en la relación con su medio, con los otros. Desde un punto de vista objetivo, esa conexión universal adquiere una forma concreta en la organización de la solidaridad como figura institucional de este ser colectivo, que busca articular y disponer el lazo humano en razón de su conexión. Para ello necesita de horizontalidad, da la ausencia de barreras y limitaciones, pero también del otro en tanto experiencia de un más allá, de un infinito trascendente. Es decir, necesita del otro en tanto otro, no como una subsumisión de lo desconocido en lo propio, en lo mismo.

Ahora bien, sobre esa relación con los otros, el cristianismo, a partir de su mal comprensión del infinito, ha impuesto una versión limitada y privativa de la bondad. Amor por el otro, por el semejante que porta consigo el apego a la identidad, a los contornos del yo, marcado por "la imposibilidad de salir de sí 
mismo", haciendo del otro un "no-yo" (Leroux 1985 159). Este atentado contra el derecho universal de comunión que lleva por nombre caridad y que se muestra como una de las expresiones más potentes del egoísmo, otro nombre de esta perseverancia en el ser. Cristianismo que "en el fondo es egoísmo" (Leroux 1985 172); crítica voraz y certera que contextualiza la cita que aún nos espera.

Así, dotado de estos nuevos elementos, podemos verdaderamente preguntarnos ¿cómo es posible que la caridad sea el fundamento de la libertad humana? Lo es, en la medida que esta relación se tienda a espaldas de su fundamento, de su medio o de su naturaleza, es decir en aras de la limitación y de sus formas, la propiedad, las castas, los nombres, las nacionalidades (recordemos que una de estas formas limitadas es la patria) y con ello la soberanía y el derecho que la sostiene. La caridad funda una libertad por tanto limitada, contingente y ciertamente objeto de primera importancia para la reflexión filosófica en tanto institución del "mal sobre la tierra" y expresión del sufrimiento.

Invitación por tanto a reconducir no tan sólo la filosofía, sino toda empresa humana sobre el fundamento que la hace posible, sobre la relación colectiva que la posibilita y a la resistencia de toda limitación de este suelo en pos del interés privativo y egoísta. Empresa de resistencia por tanto e impregnada de una sed de futuro de horizontes, hasta el día de hoy, insospechados.

\section{Bibliografía.}

Abensour, Miguel. La communauté politique des "tous uns "Entretien avec Michel Enaudeau. Paris: Société d'édition Les Belles Lettres. 2014.

Abensour, Miguel. Le procès des maîtres rêveurs.Paris : Sens\&Tonka, 2013

Abensour, Miguel. "De quel retour s' agit-il?", en Pour une philosophie politique critique. Paris: Sens \& Tonka, 2009.

Abensour, Miguel. "La extravagante hipótesis", en Para una filosofía política crítica, Barcelona: Anthropos, 2007.

De la Boétie, Etienne. Le discurs de la servidude volontaire. Paris: Singulier,2011.

Faure, Alain y Jacques Rancière, La Parole Ouvrière. Paris: La Fabrique Éditions, 2007.

Frobert, Ludovic, "Politique et économie politique chez Pierre et Jules Leroux" en Revue d'histoire du XIXe siècle [En línea], 40 | 2010, puesta en línea el 15 de julio 2013, consultado el 16 de Abril 2018. URL: http://journals.openedition.org/rh19/3992 ; DOI : 10.4000/rh19.3992. 
Leroux, Pierre. De l'Humanité. De son principe, et de son avenir.Paris: Fayard, 1985.

Leroux, Pierre. "Lettre de Pierre Leroux au docteur Deville" en Le procès des maîtres rêveurs, ed Miguel Abensour. Paris: Sens\&Tonka, 2013.

Morris William. News From Nowhere. New York : Oxford World's Classics , 2003.

Rancière, Jacques. La nuit des prolétaires.Paris: Fayard, 1981.

Rancière, Jacques. En quel temps nous vivons? Paris: La Fábrica Éditions, 2017

Rancière, Jacques. El método de la igualdad. Trad. Pablo Betesh.Buenos Aires: Nueva Visión, 2014.

Tassin, Étienne. Un monde commun. Paris : Seuil, 2003. 